\title{
LAS ISLAS DE CABO VERDE Y LA COSTA OCCIDENTAL DE ÁFRICA EN LA RUTA DE LOS PRIMEROS VIAJES A AMÉRICA
}

\author{
Dra. D. ${ }^{a}$ Marisa Vannini de Gerulewicz \\ Universidad Central de Venezuela
}

En la ruta fatigada de los primeros viajeros de Indias, un territorio se proyectaba, cual múltiple trampolín, entre el Viejo y el Nuevo Mundo: las islas de Cabo Verde, a medio camino en el océano Atlántico hacia la vasta región conocida para entonces como las Indias. Archipiélago de Cabo Verde', una pausa insular con el carácter de Europa y el paisaje de Africa, tocada por los dos continentes y con una personalidad distinta, lugar de encuentro de varias culturas, la africana, la europea, posteriormente la inda y luego la americana, enlace entre gentes y punto estrátegico enclavado en medio del mar.

Antes del descubrimiento de América, las islas, por iniciativa de Portugal y con la colaboración de navegantes italianos (Alvise Ca'da Mosto, Antonio da Noli) fueron avistadas y descritas entre 1456 y 1460; otras, exploradas por el portugués Diogo Gómez. A continuación fueron utilizadas como presidio, leprocomio, pero principalmente sede privilegiada de equipo y apresto del sistema colonial en el continente africano.

En una nueva era en la cual el mundo conocido dirige sus ojos a América, la primera mención a las islas de Cabo Verde referida a los viajes de descubrimiento corresponde justamente al primerísimo de ellos, Cristóbal Colón, el genovés al cual la Reina Isabel prestó oídos y confianza, en la carta-relación a los Reyes Católicos Fernando e Isabel, "Serenísimos, Altísimos y Poderosísimos Príncipes, Rey y Reina nuestros señores". Después de un breve resumen de los dos viajes anteriores, aún afligido por el recuerdo de los vejámenes y calumnias a los cuales fue sometido a pesar de que, como él mismo reconoce, "Vuestras Altezas me contestaron que no se preocupaban por aquellas personas y me animaban a no preocuparme por nada, ya que no reconocían anterioridad ni daban crédito a quien hablara mal de esta empresa", al narrar el tercer viaje se refiere Colón a las islas de Cabo Verde.

1 Cabo Verde ocupa el archipiélago de su nombre, integrado por las islas e islotes de Sotavento (Maio, Sao Tiago, Fogo y Brava, más los islotes Grande, Luiz Carniero y Cima) y las de Barlovento (Santo Antao, Sao Vjcente, Santa Luzia, Sao Nicolau, Boa Vista y Sal, con los islotes Raso y Branco). En su mayoria, las islas son montañosas. En Santo Antao hay alturas de más de $1.900 \mathrm{~m}$; en Sao Tiago y Sao Nicolau, de $1.300 \mathrm{~m}$. Fogo, un volcán activo de $2.829 \mathrm{~m}$. hizo erupción en 1951 . No hay rios, pero si fuentes y manantiales de las montañas. 
En aquel tercer viaje emprendido en 1498, Colón modifica su derrotero y navega a la isla de Madera por una ruta inusual, con el fin de evitar el choque con una armada de Francia que lo acechaba en el Cabo de San Vicente. Luego se dirige a las Canarias y enviando los demás navios en ruta directa por la Española a las Indias, hace vela con una nave y dos carabelas hacia el mediodía, con el propósito de colocarse sobre la línea equinoccial y seguir camino a occidente hasta que la Española le quedara al septentrión.

Es entonces cuando avista las Islas de Cabo Verde, nombre esperanzador, sugerente y asi lo han interpretado otros figurándose en ellas un oasis de verdor que mitigaba la quemante amargura del mar. Pero el estado de ánimo de Colón refleja el desengaño, el cansancio del viaje pues "en el lugar donde esperaba descanso cuando había salido de estas Indias, me fue doblado el sufrimiento", y lamenta2:

...Islas de Cabo Verde, nombre engañador porque son tan áridas que nada de verde percibi en ellas y los habitantes están todos enfermos, de manera que no me atrevi a detenerme...

Al referirse a los habitantes "enfermos" confirma la presencia de los leprosos: las islas, que ya iban adquiriendo importancia por su posición estratégica en las rutas hacia América del Sur y punto de partida para la penetración comercial esclavista en el continente africano, estaban aún destinadas a leprosario. Quizás la impresión de aridez fue debida al periódo de sequía (finales de mayo, comienzos de junio de 1498), cuando no habían aún empezado las lluvias, todo estaba extremadamente cálido y sediento; en efecto habla poco más adelante, en las cercanías del Ecuador, del "calor tórrido que creí me ardieran naves y gentes".

Este primer testimonio sobre el archipiélago, de primera mano, es trasegado posteriormente por los cronistas de los viajes de Colón, quienes comentan, amplían y recrean las primeras impresiones del Almirante, aportando cada uno una comprensión de acuerdo a su propia cultura y experiencias personales.

Así con mayor amplitud, en una considerable dimensión geográfica, reviven las islas en la narración del tercer viaje colombino del endito historiador italiano Pedro Mártir, autor de las Décadas, quien las distingue con una detallada proyección y una resonancia mitológica de su nombre ${ }^{3}$ :

...Desde Madera Colón hizo rumbo al Sur en pos de la linea equinocial... Se encuentran en aquel trayecto las 13 islas portuguesas de las Hespérides, llamadas de Cabo Verde, y poco habitadas, menos una.

Distan estas islas sólo dos dias de navegación de la Etiopia interior, que se halla hacia poniente. A una de ellas la nombran Buenavista los portugueses, y con sus tortugas se curan anualmente de su enfermedad muchos leprosos. Apartóse inmediatemente de aquel lugar, por ser el aire contagioso...

2 Colón, Cristóbal. Carta-relación a los Reyes Católicos. La Hipaniola, mayo - agosto 1498. En I viaggi dopo la scoperta, p. 213

3 Pedro Mártir. Decada I, libro VI. 
También Fernández de Oviedo aporta detalles sobre el antiguo nombre del archipiélago:

...siguió su camino con las otras tres carabelas que le quedaron a la vuelta de las islas que llaman entre los vulgares islas de Antonio, e agora se dicen de Cabo Verde, que son las mismas que los antiguos nombraban las Gorgades...

Pero quien arroja datos precisos sobre la extraña vida que conducían los leprosos y los métodos de curación con base al consumo de la carne de tortuga y mediante la utilización de su sangre cual ungüento para esparcir sobre las llagas, es el joven Fernando, el hijo de Colón, en una prolija descripción que abarca además la manera de apresar los quelonios, perseguidos en la noche a lo largo de la playa por un espectral cortejo de leprosos armados de antorchas llameantes:

...Deseando el Almirante comprender en qué forma cuidaban de los enfermos, le informó el porrugués que alli el aire y el cielo siempre eran muy templados, lo que es primera causa de salud. Y la segunda provenia de lo que comian, pues alli llegaba gran número de tortugas, de las cuales se alimentaban ellos untándose luego el cuerpo con su sangre. En poco tiempo, perseverando con estos medicamentos, los leprosos se curan. Sin embargo, los que nacen ya infectados tardan más en sanar. El motivo de la presencia de tantos galápagos es lo arenoso de la costa, por lo que en los tres meses de junio, julio y agosto vienen de la tierra firme de Africa, del tamaño de una común rodela, y cada tarde salen a dormir y desovar en la arena. Los cristianos van de noche a lo largo de la playa con antorchas encendidas o con flamas buscando el rastro de la tortuga en la arena, y al encontrarlo lo siguen hasta que dan con la tortuga la cual, vencida por la fatiga de la larga travesia, duerme tan profundamente que no advierle el cazador: Este encontrándola y dejándola volteada con la barriga hacia arriba, sin hacerle daño sigue en pos de otras, porque ellas no pueden enderezarse ni moverse del lugar donde las dejan, por su pesadez. Vuelven por la mañana a escoger las mas apropiadas y dejando libres las pequeñas, se las llevan para de ellas alimentarse...

Al paso de Colón por Cabo Verde se refiere también el discutido Girolamo Benzoni Milanés, autor de la Historia del Mundo Nuevo. Pero Benzoni, generalmente eufórico y hasta exagerado en sus apreciaciones, adopta al referirse al Descubridor un estilo escueto, mesurado y en esta ocasión sólo destaca la estación estiva como causa del gran calor que afligió a la expedición:

...Mientras en la isla Española sucedian estos desórdenes, el Almirante salió de San Lúcar el 28 de mayo de 1498 con la otra parte de la flota y dirigió las velas a

4 Historia General y Natural de las Indias, Libro III, cap. III.

5 Historie, cap. LXV (vol II, p. 24-25).

6 La Historia del Mundo Nuevo, p. 48. Esta obra que contiene acérrimas críticas al sistema colonial español, no fue traducida hasta nuestros días a pesar de lo cual dio tempranamente la vuelta al mundo en italiano, latín e inglés. Nosotros mismos llevamos a cabo la primera versión española, publicada en 1967 en Caracas por la Academia Nacional de la Historia. 
Madera, una de las siete islas de Portugal llamadas Azores. Tomó este camino por considerarlo más seguro en tiempo de guerra, y además porque muchos corsarios franceses que habian oido la fama de las riquezas de las Indias recorrian los mares en busca de botin. Ordenó que seis de las carabelas se adelantaran, y él con las otras tres hizo rumbo a Cabo Verde y siguió su viaje cerca de la línea equinoccial; sufrió muchos trabajos y calamidades por la bonanza, y también por el calor tan fuerte que hacia, puesto que estaban en el mes de junio...

Si continuáramos analizando las referencias a las Islas de Cabo Verde y a la costa africana en los cronistas e historiadores de las navegaciones de Cristóbal Colón, veríamos como ellas adquieren en la crónica americana, desde sus orígenes, un espacio propio que se va ampliando y revalorizando hasta afirmarse y conformar un importante capitulo en la literatura sobre los viajes al Nuevo Mundo.

Amerigo Vespucci, o Américo Vespucio, sigue de cerca a Colón en el paso por el archipiélago de Cabo Verde describiendo también parte del litoral del Africa, a los cuales a diferencia del Almirante se dirige directamente desde Cádiz, evidentemente bien informado, para hacer provisión de agua y leña.

Controversial y controvertido como siempre, Vespucio ofrece en varias de sus cartas, a partir de 1500, versiones ligeramente distintas de su tránsito por Cabo Verde y por las islas?. Finalmente en la famosa Lettera delle isole nuovamente trovate in quatro suoi viaggi, también conocida como Quator Americi Vesputii Navigationes (Lisboa, 4 setiembre 1504 ) las menciona cuando se refiere a su segunda navegación, luego a la tercera y finalmente a la incumplida cuarta, en la cual reconoce también la Sierra Leonas:

...Partimos (de Lisboa) a 10 dias de mayo de 1503, y fuimos derecho a las islas del Cabo Verde, donde carenamos y nos abastecimos nuevamente, estando alli 13 dias. De aqui partimos a nuestro viaje, navegando por el viento siroco; y como nuestro capitán mayor fuese hombre presuntuoso y muy tozudo, quiso ir a reconocer la Siera Leona, tierra de Etiopia austral, sin tener ninguna necesidad, sino por hacer ver que era capitán de seis naves, contra la voluntad de todos nosotros, los otros capitanes. Y asi navegando, cuando estuvimos en la dicha tierra, fueron tantas las turbonadas que nos alcanzaron, y con ellas el tiempo contrario que, estando a la vista de ella durante 4 dias, nunca nos dejó el mal tiempo desembarcar; de modo que fiumos forzados a volver a nuestro verdadero rumbo...

7 Señalamos las siguientes: una versión en la Lettera del 4 de junio de 1501 dirigida desde Cabo Verde a Lorenzo di Pier Francesco de Medici en Florencia, en la cual menciona sus esfuerzos por determinar la latitud y sobre todo la longitud, "que es cosa más difícil que por pocos se puede conocer, salvo por quien mucho vela y observa la conjunción de la luna con los planetas, y por cuya causa he perdido yo mucho sueño, y abreviado mi vida diez años", y se explaya en describir su encuentro con dos naves del Rey de Portugal que regresaban de la India Oriental y relatar las noticias recogidas (p. 127-130 en la obra que utilizamos, citada en la bibliografia); otra en la Lettera al mismo enviada desde Lisboa en 1502 (p. 143); otra aún en la carta llamada El Nuevo Mundo, supuestamente de 1503, en la cual calcula además que "desde el promontorio de Cabo Verde hasta el principio de este continente hay cerca de 700 leguas" (p. 173-177).

El Nuevo Mundo, p. 233, 249, 261, 263. El párrafo que reproducimos corresponde a la página 263. 
Continuando aún en el período de los descubrimientos y exploraciones de las nuevas tierras y de los nuevos mares, constituye uno de los más azarosos y deslumbrantes capítulos en la historia de la navegación el aventuroso viaje de Magallanes y Pigafetta, en su accidentado primer périplo alrededor del mundo.

Fueron diez y ocho hombres, o más bien diez y ocho náufragos en huesos, famélicos, agotados, descalzos y casi desnudos los que avistaron las islas de Cabo Verde el 9 de julio de 1521. No iban, sino venían de América. Conformaban los restos de la numerosa expedición del portugués Fernando de Magallanes hacinados a bordo de una sola nave, la Victoria, única superviviente de la grandiosa de la flota: diezmados por batallas, rivalidades, borrascas, hambre, enfermedades, acéfalos de casi todos los más expertos navegantes y de su glorioso jefe quien yacía en la lejana isla de Mactan, en las antípodas, caído en combate con los naturales después de una ominosa traición de su propia gente. Habían cumplido la vuelta al mundo, empleando unos tres años. Sin comprenderlo aún a cabalidad habian constatado en su travesía la esfericidad del globo terrestre, empresa soñada por muchos, y por otros considerada absurda e imposible: la teoría surgida en las nobles y prolíficas mentes de Colón y de Magallanes, de "buscar el levante por el poniente" había recibido la más evidente confirmación. Quedaron ampliadas la noción de la distribución de las tierras y de las aguas, la navegabilidad del mar en muy bajas latitudes, la configuración de la parte sur de la América Meridional, y las famosas teorias de la prolongación de Asia hacia Oriente.

Cabo Verde significaba para ellos la salvación, cl regreso seguro, el retorno a un mundo real y conocido.

He aquí como el vicentino Antonio Pigafetta, quien junto con el portugués Sebastián El Cano, ambos capitanes del infortunado Magallanes, logró vivir para completar la circunnavegación, estampa en su diario que califica de "Libreflo", redactado día a día entre las "vigilias, fatigas y preregrinaciones" los también extraordinarios sucesos ocurridos en las cercanías de las Islas donde sufrieron la deplorable pérdida de veintiún tripulantes. El mar acogió los cuerpos exánimes mientras a los sobrevivientes los hostigaba la vista de aquellos infelices entrando a su última morada, los cristianos con el rostro mirando al cielo, implorando de Dios el perdón y los asiáticos mirando al mar con el rostro vuelto hacia las profundidades que le eran tan familiares ${ }^{\circ}$.

Desconcertado, el insistente italiano comprueba además justamente allí, en las islas de Cabo Verde, que no era miércoles, como creía y tenía anotado en su diario, sino jueves. Habían experimentado el curioso fenomeno de adelanto en el tiempo, al cruzar desde América el oceáno ${ }^{10}$ :

9 Pudiera ser que por la conformación del cráneo y otras características morfológicas, o por la vestimenta, se produjera este hecho sorprendente descrito por Pigafetta.

10 Pigafetta, Relazione..., p. 174-175. Muchos años tardaria la civilización europea en comprender completamente y aceptar ese extraño fenómeno, aunque ya desde la época del Descubrimiento, Pedro Mártir intentara desentrañarlo. En cuanto a las "invenciones" mediante las cuales con "temperadas palabras" se dirigieron a los portugueses, eran necesarias ya que no podian los marinos revelar su verdadera ruta, pues habian transgredido las leyes o al menos pretensiones portuguesas sobre navegación y exportación de especias. 
...Finalmente, con la ayuda de Dios, el 6 de mayo (de 1521) cruzamos este cabo (de Buena Esperanza), cerca de cinco leguas. Si no lo hubiéramos acercado tanto, nunca lo habiamos podido cruzar: Luego navegamos a maestral dos meses continuos sin tomar abastecimiento, y en este poco tiempo murieron veintiún hombres. Cuando los echábamos a la mar, los cristianos iban al fondo con la cara mirando hacia arriba, $y$ los indianos siempre hacia abajo. Y si Dios no nos hubiese concedido buen tiempo, todos habriamos fenecido de hambre. Por fin, constreñidos por la gran necesidad, fuimos a las Islas de Cabo Verde. El miércoles 9 de julio alcanzamos una de ellas llamada Santiago, y enviamos un batel para vituallas, inventando decir a los portugueses que se nos habia partido el trinquete bajo la linea equinoccial, y que mientras nos ocupábamos en repararlo nuestro Capitán General con los demás navios habia seguido rumbo a España. Con estas temperadas palabras y algunas mercancias obtuvimos dos barcas llenas de arroz.

Habiamos encomendado a los nuestros que preguntaran qué dia era: los portugueses contestaron que era jueves. Nos sorprendimos muchisimo pues era miércoles para nosotros, y no nos explicábamos cómo nos habiamos podido equivocar: pues por cada día yo mismo, habiendo siempre estado sano, habia escrito el diario sin ninguna interrupción. Pero según luego fue dicho, no era error: el viaje hecho siempre por occidente, y volviendo al mismo lugar, como hace el sol, habia traido aquella ventaja de veinticuatro horas, como claro se ve...

Pocos años transcurren, ni siquiera dos décadas, pero es suficiente para marcar una precisa evolución en la mentalidad y en los anhelos de los viajeros a América: a la pasión por lo desconocido, el ansia por descubrir, conocer lo nuevo, perpetuar su propio nombre en arriesgadas, gloriosas empresas, suceden intereses más prácticos y personales: enriquecerse, explotar al máximo las nuevas tierras, sus productos, su gente; alcanzar poderes y privilegios. Es la era de los pequeños mercaderes de modestos capitales pero grandes aspiraciones que acudían a España en busca de expansión de sus haberes, a veces representando además a otros mayores. Persiguiendo nuevos lugares para el tráfico de mercancías, ellos surcaban el mar hacia el Nuevo Mundo, y deteniéndose en Cabo Verde, aún a costa de su sensibilidad participaban timidamente en la actividad comercial en auge: la trata de esclavos.

Con estas aspiraciones, en el año de gracia de 1539 arriba al archipiélago de Cabo Verde el gallardo y aventuroso Galeotto Cei, nacido en Florencia en 1513, emparentado con la alta burguesía toscana a través de las familias Strozzi y Médicis, al inicio de un azaroso periplo de descubrimiento centrado en la costa y tierras del occidente de Venezuela que ocuparía catorce años de su vida entre incomparables peligros y sufrimientos, con riesgo de su propia existencia.

Cei, como abiertamente admite, inicia su proyectado viaje comprando en las islas de Cabo Verde numerosos esclavos, que en un interés claramente mercantilista revendería al llegar a Santo Domingo procurándose los medios pecuniarios básicos para enfrentar otros avatares que le permitirian, en virtud de sus cálculos, tomar de América rico y famoso. 
Es extraordinariamente detallada y fiel la descripción de Cei, cuyos comentarios de inestimable valor por haber conocido en persona las Islas, ocupan las primerisimas páginas de su manuscrito: Viaje y Descripción de las Indias. 1539-1553:"1

...En dichas islas (Las Canarias) suelen tocar todas las naves que van a las Indias Occidentales, para tomar agua y vituallas, pero nosotros no lo hicimos, más bien, reconocida la isla de Hierro a diez leguas de distancia, nos dirigimos a la parte austral de la costa de Berbería, a cabo Blanco y Rio del Oro, y bordenado dicha costa enfilamos hacia las Hespérides, hoy llamadas islas de Cabo Verde, cabo que están en la costa de Guinea, a 14 y $1 / 4$ grados.

Estas islas distan de dicho cabo 480 millas y de las Canarias, es decir; de El Hierro, 800 millas o más; están a 15 grados y son la siguientes; Isla del Fuego, la de Mayo, Santa Lucia, San Nicolás, San Vicente, San Antonio, Isla de Sal y la principal se llama Santiago, y su principal pueblo San Jacobo. Estas islas Hespérides son del Rey de Portugal y las Canarias del Rey de España.

En las islas de Cabo Verde tocan todas las naves que van de Lisboa a Calicut, haciendo aprovisionamiento de agua y de todo lo necesario para la navegación. Tocamos en un puerto que llaman La Playa y también Ribera Grande, donde las naves están seguras, porque en el principal no pueden quedarse por ser su costa muy escabrosa y sólo se están alli durante 5 o 6 horas, cargando los esclavos y haciéndose prontamente a la vela...

El ocurrente y minucioso viajero convertido en cronista de Indias, se extiende en forma amena sobre las características y maravillas de las Islas de Cabo Verde que encuentra fascinantes. Exalta la riqueza del suelo y la gran producción de que pueden abastecerse los navegantes, así como la extraña mescolanza de razas que lo asombra y cautiva. La bullente población, abigarrada y heterogénea, admitía en su seno multitud de parias, sin destino conocido, transgresores de todas las leyes, prófugos de la justicia que se dedicaban a la pillería de las naves y de algunos navegantes que de buena fé confiaban en los nativos, quienes sin embargo eran en su mayoria honestos y afables.

...Permanecimos en la isla Santiago 3 semanas, para comprar esclavos, destinados a la isla de Santo Domingo: nos costaron 36 ducados cada uno, que hoy valen más de 70 ducados, y se compraron 250, entre machos y hembras, Yo compré 40 de ellos y recorri por cierto buena parte de la isla, que es muy pequeña, no creo que tenga 90 millas a la redonda, es muy áspera y montañosa, que si no es sobre pequeñas mulillas no se puede cabalgar: Es tierra muy cálida y enfermiza y cotidianamente brota un poco de pestilencia; es muy humeda por las constantes lluvias y asaz bien cultivada en ciertos valles donde hay algunos pequeños ingenios de azucar, cosa de poca monta...

11 El manuscrito de Cei fue recientemente localizado, transcrito, comentado y editado en ltalia por el Profesor Francesco Surdich (Roma, Bulzoni Ed. 1992). La primera traducción al español fue realizada por nosotros en Venezuela, y publicada en 1995 en la Colección V Centenario del Encuentro entre Dos Mundos. Los párrafos que transcribimos a continuación corresponden a las págs $5,6,7,8$, de la edición venezolana. 
...Está poblada por portugueses, ya que en Portugal, a cambio de enviar los hombres a galeras o ajusticiarlos, los confinan, a manera de degradación, en estas islas, de modo que alli está la flor y nata de los pillos y rebeldes. Muchos de ellos llevan largos cabellos, para que las moscas no les entren en las orejas; se maridan con las esclavas negras, etiopes, o con mulatas, que son hijas de blanco y negra, de las cuales hay gran cantidad, tanto en Portugal como en España, por la cual ocurre que en estos reinos existen extrañas caras y colores de personas, a causa de tales mezclas... Las mencionadas islas están pobladas de bandidos y cristianos nuevos, todos muy prestos al engaño y se necesita ser bien diestro para no dejarse engañar..

Con agudo espíritu de observación, haciendo gala de su cultura renacentista y de un dejo de humorismo, Cei describe con vívidos detalles la fauna y flora del archipiélago, maravillado ante tantas especies nuevas, asombrado de la abundancia del lugar de la variedad de la vegetación silvestre y valorizando los grandes y pequeños habitantes del lugar, tan frecuentes en su época, y hoy quizás en gran parte desaparecidos:

...Hay muchas cabras, asnos, mulillas salvajes y yeguas, traidas de Portugal, caballos hay unos cuantos, tamibén vacas, carne en razonable cantidad; hay asi mismo, vino, aceite y harina, que provienen de España y de Canarias, y también se comen buenos higos, traidas las plantas de Canarias.

No nace alli otro grano que no sea el maiz de Indias que los portugueses llaman "mijo Brasil"; el arroz viene de Cabo Verde. En dicha isla hay nueces grandes que llaman de India aqui y allá les dicen cocos. El árbol que las produce es como una palmera aunque no tan alto y con las ramas más biertas, y entre ellas se ven los racimos de 10 o 12 de estas nueces, que es maravilla cómo pueden sostenerse en el ramo, pegadas a él por un pequeño pedúnculo.

Igualmente hay alli una gran cantidad de monos ladrones que ocasionan gran perjuicio a la caña de azúcar y al maiz, al cual roen el tallo por la base y luego se lo echan a la espalda teniéndolo con las manos, arrastrándolo por detrás colgado hasta los pies, $y$ van en fila, de modo que los portugueses los llaman suizos, porque parecen soldados con la pica a la espalda.

Hay alli una suerte de gallinas que dicen de Guinea, grandes como faisanes, negras, grises, moteadas de blanco, de vuelo como el de las perdices, la cabeza roja, de tan buen sabor como aquellas y las hay en gran cantidad y son baratas, a diez cuartillos cada una. Dicen que las han traido de Guinea y Berberia, y he visto muchas en Marruecos y cabo Guey, pero no son tan buenas como en estas islas, ni con mucho...

Apoyándose en detalles precisos narra el mercader el modo en que se conducía hacia América la carga de esclavos y la forma en que se les alimentaba y vigilaba, aportando interesantes datos anatómicos sobre los africanos y sus características raciales, que no dejan de sorprenderle por no haber estado jamás en contacto con ellos. Acostumbrado a su plácido y pequeño ambiente florentino, y siendo la primera vez que se atrevía a explorar otros lugares, hace gala sin embargo de un estilo pintoresco en relatar de la cautividad de los negros, y retratar su gastada y humillada humanidad: 
...Los esclavos que se compran en esta isla provienen de Cabo Verde y de Ribera Grande, también de otros puertos de Etiopia, de tal suerte que los negros que aqui se ven, dicen que son hijos vendidos por sus padres, pero la mayor cantidad es apresada en las continuas guerras entre ellos. Los llevan en carruajes todos desnudos, tal como andan en Guinea: los machos tiene un trozo de cuero que apenas les cubre las nalgas, con una correa que pasan entre las piernas y se enrollan en torno al miembro viril y a la cintura, manteniendo el miembro pegado a la piel, de modo que sólo se le ven los testiculos. Son muy aficionados a bañarse en los rios, donde los veréis en gran cantidad, por más de dos horas, lavándose, no veréis su miembro, que lo esconden entre sus muslos y está provisto de tal longitud, que bien pueden hacerlo. Las hembras llevan un trozo de tela de algodón a rayas negras, azules y blancas envuelta en torno a sus flancos hasta media cadera, con copiosas de asentaderas más aún si son paridas, lo cual es cosa fea en extremo... Esto es cuanto os puedo decir de esta gente: una nación es enemiga de la otra; los más valientes son los llamados jolofos y los bereberes, y los mejones son los biafras y zapes; los de menor valor son los manicongos, pero ésios van a la isla de San Tomé...

A pesar de haber adquirido esclavos para su uso personal y su provecho, lo que era usual para la época, Cei protesta por la forma cruel en que éstos son tratados, y la manera bestial en que los obligaban a realizar el viaje hacia América, sedientos, mal alimentados, casi sofocándose y sin ninguna esperanza de nada, pues la mitad moría antes de llegar a su destino. Manifiesta una dudosa contrición (i sentido humanitario o interés comercial ?) cuando parece preocuparse más por sus esclavos que por los avatares la navegación, de la cual apenas menciona el arribo el 22 de octubre de 1539 y una "tempestad grandísima" que la azotó:

...Partimos de dicha isla el 18 de septiembre con 250 esclavos, y entre marineros y pasajeros 60 personas, que en total éramos más de 300 personas. Los esclavos estaban bajo la primera cubierta, amontonados como sardinas, cerradas las escotillas de noche, con buena guardia; de dia salian fuera, de 6 en 6 o de 10 en 10, más o menos, y como hacia alli tanto calor, exhalaban un olor de almizcle bastante desagradable; pagábamos de flete y comida 5 ducados al maestre de la nave por cada esclavo y la forma de alimentarlos era la siguiente: diariamente, a medio día, hacia su aparición un gran caldero con arroz cocido, o con maiz de Indias ya desgranado, y de 6 en 6, más o menos, en ciertas vasijas de madera, se les daba de comer y quien queria hacerlo más grato le daba un poco de aceite que comian con aquello y del que eran muy golosos. Después de comer se les daba de beber en un gran cazo lleno de agua, donde se inclinaban y bebian como bestias, con un guardia que tenia mucho cuidado de que no bebiesen más de lo que alcanzaran a ingerir en un solo trago y si alguien se sobrepasaba, lo azotaba con un buen fuete, porque de otra manera, toda el agua que la nave llevaba se acabaria apenas en 4 dias de viaje.

Antes de que se les diese de comer, todos los cristianos se retiraban al castillo de popa y la de proa, con sus armas prontas, los arcabuces cargados y personas en las gavias, con piedras $y$ dardos, y cada uno a la vista y en guardia, porque siendo tantos, ha ocurrido que matan a los cristianos y si no fuese que son de diversas naciones y 
enemigos los unos de los otros, seria imposible conducirlos y manejar tandos de ellos. De igual manera,además, se mantenia encadenados a una docena de principales que solo comian y bebian una vez al día. Y con esta vida en 35 días llegamos a Santo Domingo, isla llamada La Española, alli se murieron 12 de estos esclavos de viruelas, que es para ellos como para nosotros la peste...

Nos acercamos a finales del siglo XVI. Encontramos las relaciones sobre el archipiélago de otro toscano, Filippo Sassetti, (nacido en Florencia en 1540, fallecido en Goa, India, en 1588), experto asesor financiero y contable de varios banqueros, quien escribe primero como observador y comentarista de experiencia ajenas, y luego como viajero presencial. En la época en la cual los Médicis, Señores de la ciudad toscana, impulsaban y auspiciaban los viajes, el comercio, la redacción de informes, Sassetti se aventuró en España, Portugal y luego India dejando una colección de cartas de gran valor geográfico, las cuales sin embargo vinieron a ser publicadas en su integridad tan sólo en 1970, en Milán, con el título "Lettere da vari paesi, 1570-1588".

En una misiva escrita el 10 de octubre de 1578 a Baccio Valori de Florencia, desde Lisboa donde representaba los intereses de algunas casas comerciales florentinas mientras preparaba su propia incursión hacia la India, Sassetti se refiere a las islas de Cabo Verde ofreciendo peculiares detalles sobre la navegación y tráfico de los lusitanos, el comercio de la región y los precios. Estos datos recogidos en Portugal por el florentino que valiéndose de un verso de Petrarca juzga a los portugueses "dure genti e costumi" (rudas gentes y costumbres) para tratar con los cuales hace falta una extremada paciencia, al punto que aconseja a quien sea veloz en sus movimientos huir del lugar antes de morir alli súbitamente, reflejan la visión de las islas también desde la perspectiva de los grandes y poderosos mercantes que iban y venían de las Indias Orientales y Occidentales comerciando con esclavos, cueros, telas, oro y almizcle y con la preciada caña de azúcar'

...El tráfico de los portugueses es en Caboverde y aquellas islas cercanas, más abajo de la Mina de San Jorge y toda esta costa de Africa que mira a poniente; en la isla de San Tomé (Golfo de Guinea), y en aquella costa del Mundo Nuevo que llaman Brazil. De alli por el Cabo Buena Esperanza hacen escala en Mozambique y luego van a la India: y de la primera costa de Indias, donde están Calicut y Goa, van a Malaca, a la China, al Japón y antes a Maluco y en la costa de Africa de poniente, que son Caboverde y la Mina. Llevan principalmente las telas de Indias en cantidad grande y las de Roano (Francia), otras trabajadas de varias formas y especialmente collares y ciertos anillos que aquellos negros se ponen en la nariz y en las orejas y muchas cuentas de vidrio, con las cuales hacen gargantillas y collares y algunos rojos que vienen de India.

A San Tomé no llevan sino las cosas necesarias para la alimentación ya que, exceptuados los portugueses, no hay otros sino esclavos... Y las cosas que traen de vuelta son éstas: de Caboverde cueros, algodón, azúcares; de la Mina oro perfecto y almizcle, que este año que los portugueses están en guerra con los del pais, en dos bar-

12 Hemos seleccionado y traducido los párrafos siguientes de Lettere da vari paesi, Lettera LVI, p. 216-223. 
cos han servido más de docientos mil ducados en barritas de oro. De San Tomé vienen aquellos azuicares que se refinan, que llaman azúcares rojos, en número de siete millones y seiscientos mil libras de las nuestras, y cada treinta y siete valen alrededor de un ducado y tres cuartos...

Es espeluznante la descripción que Sassetti traza del tráfico de esclavos y de los esclavos mismos, uno de los más antiguos testimonios de este floreciente aunque abominable comercio, que presenciara en una de sus etapas finales, el arribo de los negros a los puertos portugueses:

...De San Tomé viene una gran turba de negros traidos de toda la costa de Africa, de Caboverde hasta aquel paralelo. Son ellos ciertamente gente más de fatiga que de intelecto; los que provienen del Caboverde, de todos los negros son los más gentiles, $y$ con facilidad aprenden todo lo que ven hacer, hasta tocar la flauta y sobre todo sostienen bien las armas en su mano. De ellos se tiene buen servicio, con la salvedad de que son algo soberbios, lo que es un vicio de todos los negros, y hay el dicho "tiene más arrogancia que un negro". Es una tristeza ver como son llevados acá que en un barco habrá unos veinticinco, treinta, cuarenta y todos están en la cubierta desnudos, uno encima de otro. Se acostumbran muy abstinentes, que hasta acá les dan de comer lo mismo que en su tierra, ciertas barbas como las de batata, que crudas o cocidas, quien no lo supiera las juzgará castañas...

Sigue un impresionante semblanza del mercado de esclavos, que fue prosperando con el descubrimiento y la necesidad de siervos para los trabajos en las productivas provincias americanas, a favor de las arcas españolas o europeas:

...Puestos en tierra, son expuestos a pleno sol en turnos, y quien quiera comprarlos alli va y los mira en la boca, les hace extender y doblar los brazos, arrodillarse. correr y saltar y todos los demás gestos y movimientos que puede hacer un hombre sano lo que, considerando en ellos la naturaleza común, no puede ser que no les dé susto, y su precio es de treinta hasta sesenta ducados cada uno...

Digna de la literatura circense nos parece la estampa que traza a continuación Sassetti, en vívidos colores, casi excusándose con su señor Baccio Valori por concluir la carta con esta "historieta de poco gusto", quizás hasta contraria a los más elementales principios de la trata de esclavos, los cuales - dice el ocurrente florentino- no siempre se pueden acatar como hasta acepta Platón, aunque no deja de apuntar que ni Valori ni los demás toscanos los dejaban de observar jamás:

...No puedo dejar de contar a lo me hizo quedar atónito, considerando su miseria y la inhumanidad de sus dueños. En una explanada habia en el suelo quizás cincuenta de estos animales, que formaban de ellos un circulo: $y$ los pies eran la circunferencia, y la cabeza el centro, estaban uno encima del otro, y hacian fuerza para ir a tierra. Yo me acerco para ver que juego era ése, y veo en el suelo una gran ponchera de madera, donde habia habido agua y aquellos miserables estaban y se esforzaban por chupar las gotas restantes y lamer el borde; y parecióme que entre ellos, asi en la acción como en el calor, y un hatajo de puercos que se pelean para meter el hocico en el rancho, no habia ninguna diferencia... 
En otra carta escrita a Michele Saladini posteriormente, en 1585, después de haber realizado su propio infortunado viaje a las costas de Brasil, y por tanto haber observado más de cerca y por si mismo el archipiélago, proporciona una descripción atenta y equilibrada de las condiciones atmosféricas, sobre todo de los vientos ${ }^{33}$ :

...Atravesando yo, o mejor dicho pasando las Canarias para venir a la India, se viene por mediodia y tramontana frente a esas islas, y se pasa por entre las islas de Caboverde y la tierra firme, y se va recto lo más que se puede en altura de cuatro grados de nuestra banda, donde se encuentran los vientos que llaman generales, los cuales normalmente empiezan a soplar desde siroco. $Y$ con estos hay que pasar el eje equinoccial, poniendo la proa por Garbino; y a quien se encuentra más cerca de la tierra de Etiopia y le dan esos vientos, hace mejor navegación, porque se halla más en ventaja: los portugueses dicen más abal devento, sopra vento dirian los nuestros. Al atravesar la línea tienen en consideración un escollo que llaman el Penedo de San Pedro, que quien lo deja más al poniente ha hecho mejor navegación, y quien lo pasa de cerca necesita que Dios le ayude. Estos vientos sirocos suelen ir al levante y a veces a grecolevante con los cuales se pone la proa a mediodia y mediodia y siroco; y si se hace buena navegación, se pasa cerca de la isla que llaman de Martín Vas. Quien se queda con los sirocos como nosotros hicimos la primera vez, llega a la costa de Verzino; y mientras se tenga a la vista, me encomiendo a Su Señoria, pues a volver atrás se tiene buen pacto...

El desarrollo de esta carta abarca la descripción de la costa de la antigua Etiopia, muy detallada si consideramos la dificultad que revestía en la época su observación, a causa de lo precario de la navegación y el celo de los portugueses que impedían acercase a ella.

Es de destacar la frialdad con la cual Sassetti, acostumbrado y resignado, se refiere ahora al comercio negrero con otra mirada, ya no la del maravillado aventurero, pasmado ante lo que sus ojos observaban por primera vez, sino con la visión del hastiado comerciante, acosado por las penurias de la travesía y familiarizado con lo que antes pareciale inconcebible:

...En la costa de Etiopia tienen los portugueses la primera fortaleza, pasando la primera tierra de los mares que se llama Arguia, en las islas de Caboverde; y me parece que delante de la Mina tienen otro castillo en la costa de Maleguetta sin más, por amistad y comercio por todos esos rios más abajo del Congo, Sumicongo y Angola, donde van de San Tomé, y de Lisboa a comprar negros. Y todos estos rios son hoy, portugueses, y muchos de aquellos negros son cristianos sujetos al obispo de San Tome el cual me decia en Portugal que son muy gentiles cristianos. Y Migliorati, que estaba presente, contestaba: Así lo creo yo...

Al ocaso del siglo XVI, en el umbral de una centuria que signaría una revolución económica en Europa con el aporte de las nuevas colonias en las cuales empezaban a afianzar-

13 Lettere da vari paesi, Lettera III, p. 458-465. 
se firmemente asentamientos europeos, Francesco Carletti, otro joven navegante florentino ${ }^{14}$ avistó las islas a los diez y nueve días de un viaje iniciado el 8 de enero de 1594 y que, sin que fuera ésta su intención, lo llevó a dar la vuelta al mundo, como relata en su obra Ragionamenti sopra le cose da lui vedute nei suoi viaggi si nelle Indie Occidentali e Orientali come l'altri paesi (1594-1606) ${ }^{15}$, publicada en Florencia en 1707.

En plena juventud, con el vigor de sus 21 años entusiastas y optimistas, la visión de Carletti regocija por el tono entre humorístico y satírico. En su Primo Ragionamento enfoca la isla de Santiago, centro del mercado esclavista negrero, donde atracaron y permanecieron casi tres meses (de enero a abril de 1594), retratando pícaramente la vida holgada y placentera de los portugueses, sus gustos por las mujeres de color cuya hermosura, sensualidad y complacencia parece haber comprobado ${ }^{16}$ :

...La isla de Santiago, donde nosotros atracamos, dista 16 grados de la línea equinoccial hacia tramontana: de España alrededor de 1500 millas, y de la tierra firme de Cabo Verde en el continente de Africa 300 millas. En ella hay una pequeña ciudad llamada Nombre de Dios, con un puerto no muy grande expuesto hacia mediodia. Tiene su obispo, y unas cincuenta casas de portugueses casados, algunos con mujeres blancas de Portugal, otros con negras de Africa, otros aún con mulatas, es decir nacidas de hombre blanco y de mujer de color. A estas negras aman más que a sus propias portuguesas, teniéndose por cierto y comprobado que tratar con ellas es menos dañino y de mayor placer, pues son de naturaleza más genuinas y sanas...

... Volviendo al tema de los portugueses que viven en estas islas, es cierto que más aprecian a una mujer negra del pais, que a una blanca de Portugal. Parece que el clima influye en que se deseen más las naturales que las extranjeras, y se ve por observación propia que quien no las tiene por esposas procura tenerlas por concubinas. Con éstas luego, vencidos por el afecto, al fin se casan y viven mucho más contentos que si fueran de su nación. Pero es también cierto que muchas de estas negras, en valor, inteligencia, simpatía, disposición del cuerpo y armonia de los miembros, excepto en el color, superan en mucho a nuestras hembras. $Y$ en esto confieso que me incluyo también yo, porque algunas me han parecido hermosisimas y su color negro no me molestaba para nada, tal como se ve que le sucede a los portugueses que se acostumbran a verlas dia tras dia...

Igualmente se muestra atraído y fascinado por los diferentes juegos y diversiones de la isla, sobre los cuales se extiende con hilaridad:

...Hay un numero infinito de esos monos de cola larga que nosotros llamamos micos, y los portugueses bugios, a los cuales les enseñan a bailar y a hacer juegos $y$ bufonadas. He visto algunos que habian aprendido a estar de pie en una esquina de la

14 Francesco Carletti nació en Florencia en 1573 y falleció en la misma ciudad en 1636.

15 Traducción: Razonamientos sobre las cosas vistas en sus viajes en las Indias Occidentales, Orientales y en otros países.

16 Extraido de Primo Ragionamento. 
mesa con una vela en la mano, alumbrando a los que cenaban, con un extraordinario cuidado de no gotear el esperma sobre el mantel ni cometer ningun otro error; y frecuentemente al estar la vela cerca de acabarse, y ellos de quemarse, se la iban pasando de una a otra mano para no abrasarse, antes que dejarla caer. Esto no lo hacen sino al último momento, obligados por no poderla ya sostener; mas torciendo la boca y batiendo diente con diente como para explicar la causa por la cual la tiraron, lo que sin embargo hicieron cuidando de que no cayera sobre la mesa. Lo mismo le exigen los portugueses a sus esclavos, los cuales deben alinearse desnudos a las cabeceras de las mesas con velas en las manos, mientras los amos comen y conversan, sirviendo de candelabros tan eficientes como si fuesen de plata...

En el Secondo Ragionamento se hace evidente la repugnancia de Carletti por el comercio de esclavos, que sin embargo profesa y como muchos de sus contemporáneos explota para su beneficio sin protestar, pues en tales consideraciones humanitarias no podian manifestarse abiertamente, para no atraer las burlas y comentarios de todos ${ }^{17}$ :

...Compramos setenta y cinco, dos tercios varones y el otro tercio hembras, mezclados todos al uso de aquel pais, en una manada de viejos y jóvenes, grandes y pequeños, como se compra entre nosotros un rebaño de ovejas, con todas las precauciones $y$ cuidados de averiguar si están sanos, bien dispuestos y sin defecto alguno de su persona. Luego cada amo los hace sellar, es decir, marcar con su propia marca de plata calentada en fuego ardiente y aplicada en el pecho, o en los brazos, o en la espalda para reconocerlos. Y cuando recuerdo que yo mismo hice esto por orden de quien tenia poder sobre mi, me agobian una gran pena y confusión de conciencia, pues en verdad, Serenísimo Señor, éste siempre me pareció un tráfico inhumano e indigno de la fe y piedad cristianas: pues se actia con crueldad y violencia sobre carne y sangre humanas, y tanta mayor es la vergüenza, en cuanto están bautizados, y aunque son diferentes en el color y en la suerte, tienen sin embargo la misma alma forjada por el mismo Hacedor que forjó las nuestras. Yo me disculpo ante la Divina Majestad, pues aún sabiendo Ella que a mi sentir y querer fue siempre repugnante este negocio, fue es menester haceno: pero sepa Vuestra Alteza y tengalo por seguro, que a mi ese tráfico no me agradó nunca, mas como fuere, nosotros lo hicimos y quizás también por ello. tuvimos que hacer penitencia, tal como diré al final del segundo discurso de estos razonamientos, que yo iré haciendo a V.A.S. de todos nuestros sucesos...

Fue efectivamente desventurado el epílogo de la navegación de Francesco Carletti. Viajaba con el padre, al cual perdió en Macao, y cuando de allí costeando Sumatra, las Nicobare y Ceylan alcanzó Goa y se preparaba a regresar a Europa con algunas riquezas cerca de la isla de Santa Helena fue capturado por naves holandesas que le confiscaron todos sus haberes. Agradeciendo a Dios haber salvado la vida, el apesadumbrado toscano se resignó a la pérdida total de su patrimonio, interpretándola como un castigo divino por haber comerciado con esclavos africanos.

17 Extraído de Secondo Ragionamiento. 
Navegación, exploraciones, comercio, contrabando, trata de esclavos se mezclan y confunden en las observaciones de tantos navegantes que, ya superado el periódo del descubrimiento, se acercan a la costa africana y a las islas, como primera escala en la ruta hacia más lejanos horizontes. Sin embargo también encontramos algunos idealistas, llevados por el ansia de aventura, y éstos quizás nos aportan una más serena y ecuánime visión de ellas.

Es el caso del gentleman inglés Sir Robert Dudley, quien antes de cerrarse el siglo dieciseis, se acerca al archipiélago rumbo al Nuevo Mundo proveniente de la aristocratica Inglaterra isabelina, equipado como corresponde a un navegante de su clase con su propia flota de descubrimiento, sus capitanes, pilotos, tripulación, tropas y armamentos, en pos de nuevas tierras para la gloria de su Reina, y también de azarosas batallas en los mares para probar su valor y osadia. En realidad Dudley habria querido surcar las peligrosas aguas del Pacífico tras el rastro de tesoros y maravillas que tantos viajeros referían haber hallado en las Indias orientales Pero lamentablemente para él una muy prudente disposición real quizás dictada por el deseo de proteger al hijo del amante de la Reina Isabel ${ }^{18}$, tomando en cuenta su extremada juventud (aún no cumplía los 20 años), se lo prohibió. Con gran despecho de su parte se vio obligado a replegarse sobre un "modesto" itinerario hacia la isla de Trinidad, en la estela de Walter Raleigh. De este anodino, mas interesante y sin duda representativo viaje nos han llegado tres relaciones diferentes, aún casi desconocidas: la del propio Dudley, Almirante de la flota; la del Maestre Abraham Kendall; la del Capitán Wyatt. En todas ellas aparece la costa occidental africana en una certera, sincera y ajustada captación del año 1594-95.

Concentrado en la conservación de su flota y en el afán de medirse en batalla naval con los enemigos de su reino para obtener ansiados trofeos, el joven Almirante dedica escasa atención a la costa africana, a la que encuentra estéril y pedregosa, no hallando belleza en el paisaje ni hospitalidad en la región; todo lo cual expresa como corresponde a un culto hidalgo de la época en un estilo limpido y garrido, pero distante e impersona ${ }^{19}$ :

...Reconfortado, con el alivio de esta pequeña y reciente armada, cual viajero solitario y pensativo continué mi rumbo hacia las Indias Occidentales, dirigiéndome primero a Cabo Blanco, en el continente africano, cercano a los desiertos de Libia. Seguía abrigando la esperanza de volver a ver mi barco perdido, y queria además renovar mis provisiones entre los canthers, que son pescadores portugueses; pero habian sido tan atemorizados por los franceses, que no logré encontrar a ninguno. Vagando en ese Cabo Blanco dos dias, y bordeando la orilla para ver el pais, lo encontré yermo, estéril, lleno de arena arrastrada en montones por el viento como nieve, y muy pedregoso. Porque tal es todo el pais, arena sobre piedra (como el desierto de Arabia, y de Petrea), lleno de negros lagartos venenosos, con algunas bestias salvajes y algunos moros cur-

18 Robert Dudley era hijo de Sir Robert Dudley, Conde de Leicester, notorio amante de la Reina lsabel.

19 Este y los trozos siguientes referentes a la navegación de Sir Robert Dudley y su tripulación han sido extraidos de nuestra propia traducción al castellano, aún inédita, de la obra The Voyage of Robert Dudley to the West Indies and Guiana (1594-1595). 
tidos por el sol, tan fieros que apenas hablaban con la gente de mis barcos desde la orilla, muy cerca de la cual habiamos fondeado...

Sin ningún interés por lo que considera una navegación menor, ni por explorar esos territorios, considerando además la costa infecta, se aleja de ella rápidamente:

...Pero, no deseando prolongar mi permanencia en esta región a causa de los infecciosos serenos, o sea rocios que caen a lo largo de las costas de Africa, ordené a mi maestre Abraham Kendall seguir hacia la isla de Trinidad en las Indias Occidentales...

El segundo relato de la expedición nos ha llegado como:

El Primer Portulano del doctísimo marinero Abram Kendall, inglés, en el viaje en el cual navegó como piloto mayor a las Indias Occidentales con el mismo autor que entonces era General: calculando la longitud desde la isla de Pico en las Azores.

Haciendo alarde de una extrema precisión digna de un especialista de nuestro tiempo, mediante un lenguaje técnico y exacto Kendall aporta valiosos datos geográficos y meterológicos sobre la costa occidental de Africa, con numerosos detalles que reflejan los amplios conocimientos que como Maestre poseía. De una exactitud sin igual, su portulano ofrece una visión clara y fiel del recorrido costero, y pone de manifiesto el interés por constatar datos y señalar nuevos derroteros.

...Desde la isla de la Palma, del lado de poniente de la misma, en latitud de 29 grados y 0 minutos, 8 grados y 50 minutos de longitud se mantuvo mediodia lebeche medio cuarto austral con el navio hasta a 26 grados y 24 minutos de latitud hacia el Cabo Blanco en Africa; la variación fue de 3 grados gregales. Proseguimos luego el rumbo de mediodia hacia siroco, a 23 grados y 50 minutos encontramos 30 pasos de fondo, sin ver la costa de Africa que es baja y arenosa y tiene también el lecho arenoso; alli observamos hierbas traidas por la corriente del rio de Oro. Mantuvimos después dicho rumbo, o cuarto de mediodia hacia siroco, hasta encontrar que el barco habia sobrepasado un poco el Trópico de Cáncer a 23 grados y 20 minutos de latitud. El fondo era de diez pasos, arenoso: los vientos gregales y fijos, con buen tiempo. Se siguió la costa a vista de la tierra, a una distancia de cuatro leguas, la cual es baja y arenosa, como también le lecho es de arena, igual de ocho a diez pasos. En el camino se veía el cabo de Barbas de 21 grados y medio aproximadamente de latitud y 9 grados y 50 minutos de longitud. La viariación era de 3 grados gregales. El Cabo Blanco está en latitud de 20 grado 24 minutos y 9 grados 50 minutos de longitud. La marea mayor, hacia el cabo, es a las nueve y tres cuartos. Se anclaba por mediodia hacia lebeche, a tres millas de distancia del cabo, a seis pies en medio de fondo arenoso así como es la costa. Los vientos son grelages y fijos, con buen tiempo hasta las Indias. El dia 6 de enero de 1595 se ancló en dicha bahía y a la entrada el fondo era de 13, 9, 10,8,7 y 6 pies y 8, 7 y 6 y medio donde se anclaba; y más adentro en la bahía el fondo no estaba a más de siete ni menos de tres pies. El secano por mediodia lebeche, desde el cabo, es grande y se encuentra a unas dos leguas y media de distancia; alli adentro, los portugueses recogen gran cantidad de pescado con ciertos barcos denominados can- 
ters. Aqui no se encuentra agua clara por tratarse de un paraje arenoso y desierto; si bien haciendo pozos en la arena cerca del mar, se la encuentra dulce, pero no es muy saludable para tomar; aunque sirve cuando la necesidad apremia...

La tercera relación, la más amplia y detallada, es la del capitán Wyatt. A él justamente se debe el hecho de que la flota bordeara la costa africana. Advirtiendo la dificultad que tenían los navíos de Dudley para sobrepasar las Canarias hacia el Atlántico, debido a que los vientos los llevaban en dirección contraria, sugiere al General navegar hacia Cabo Blanco:

... "Tenemos", le dijo, "10 ó 11 días aqui, mucho tiempo para un viaje tan corto, intentando hacer velas hacia las islas de la Gran Canaria, para cumplir la cita con nuestra Vice-Almiranta; de cuán imposible sea hacerlo, Su Honor mismo ha sido testigo ocular, con gran peligro para su propia persona y gran riesgo para sus barcos. Por tanto, necesariamente, es preciso navegar hacia Cabo Blanco. Permita demostrar con su honorable consentimiento que correctamente acepta esta proposición". Consintió de buen grado el General, no sin reflexionar sobre la inestabilidad de las determinaciones de los hombres...

Menciona que la región está habitada por pescadores y ofrece una somera descripción del recorrido:

...El mismo día, sábado cuatro de enero, navegamos a la vista de la isla del Hierro, hacia Cabo Blanco. A dos jornadas de distancia, nuestro General hizo adelantar las carabelas, porque queriendo aprovisionarse temia que los pescadores portugueses se asustasen y retirasen al vernos todos juntos, impidiéndonos hacerlo. Con pocas velas nos acercamos a la costa del continente de Africa, siendo la primera tierra que encontramos Riodore, parte del reino de Asanaga. La siguiente fue Cabo Cyprian, una región del reino de Gualata, después Cabo Barbis y por fin Cabo Blanco; los dos cabos están ubicados dentro de los límites de los desiertos de Libia...

En Cabo Blanco, punto frecuentado por barcos de diversas nacionalidades, los ingleses sostuvieron un combate con navios franceses, después de capturar varias carabelas españolas. Considerándolo sitio de paso y ruta habitual para otras embarcaciones, dejan alli varios recordatorios:

...Colocamos algunos mensajes dentro de una caja de madera que tenia esta función, para repetir a nuestro Vicealmitante que debia seguirnos de acuerdo a las instrucciones que le habiamos mandado desde Plymouth hasta Famouth...

Destaca el agudo Capitán la aridez de la tierra africana y la gran cantidad de lagartos que se conviertieron en distracción y solaz de los marineros. Llama la atención el espiritu que animaba a estos linajudos marinos británicos quienes ajenos a cálculos de tráfico esclavista, indiferentes a la codicia por las mujeres, con típica flema inglesa se dedicaban a observar a los animales y a divertirse cazando raros ejemplares silvestres:

...El ocho de enero, por la mañana, desde el mar pudimos ver nuestras dos carabelas acercarse y echar anclas. Al mismo tiempo, divisamos velas a unas cuatro leguas de distancia; el General envió entonces su bote a las carabelas, ordenándoles acercarse a aquellos barcos para determinar su origen, ya que él mismo habia decidido 
bajar a tierra, lo que hizo al regresar el bote, con una tripulación de doce hombres, para hacer un reconocimiento del lugar.

No encontrando nada de interésante para descubrir, volvió al barco rápidamente, sin sorprenderse por no ver a nadie cultivando aquel desierto inhabitable, que no tenia abundancia de nada salvo de montones de arena, rocas escarpadas y unos huesos dispersos, vestigios de animales devorados por algunas bestias más voraces que ellos mismos. Durante el regreso vimos varios lagartos, cuya huida veloz propocionó gran diversión a nuestros hombres que se entretuvieron persiguiéndolos...

El relato de Wyatt ameno y en cierta forma novelesco, revela sin embargo datos precisos: habia agua fresca en la isla de San Antonio, existían manantiales, pero el lugar era considerado infecto, lo que indica que alli aún moraban los leprosos:

...El día nueve de enero, jueves, habiendo dado las gracias a Dios por tener a su gente sana y salva y a sus carabelas libres de peligro, nuestro General dio orden de proseguir hacia una de las islas de Cabo Verde llamada San Antonio, donde nuestros tripulantes esperaban encontrar agua fresca.

Esto se iba a hacer, pero el Maestre desaconsejó al General acercarse a la isla, pues era un lugar pestilencial debido al aire infectado que podia contagiar a los marinos. Por tanto decidieron entre ellos dos, en secreto, pasar de largo sin detenerse, y lo hicieron tan acertadamente que nadie se opuso, si bien más por ignorancia que por consentimiento. A la vez nuestro General, para no perder más tiempo, prohibió todo intercambio entre barcos hasta que llegásemos a las Indias, y para evitarlos proveyó a las carabelas con suficientes provisiones.

El trece de enero nos dimos a la vela para las Indias, sin cambiar nuestro numbo hasta que arribamos con suerte a Trinidad...

En este vasto panorama de testimonios de viajeros, no podian faltar los piratas, corsarios, bucaneros y filibusteros que aún bajo el signo del tráfico negrero, la lucha armanda, el pillaje, el saqueo, la quema y la destrucción, dejaron constancia escrita de su paso por las islas y costas que nos ocupan.

Hemos tratado de recoger las voces más significativas de algunos de ellos. Fueron en su mayoria navegantes ingleses, ya por la ruta que debían seguir, evitando los establecimientos españoles, ya porque durante el entresiglo XVI-XVII menudearon sus incursiones al Nuevo Mundo, impulsados por el contrabando, la represalia, la afirmación del poderío naval británico, la exploración como preludio a la consolidación de un imperio inglés en América, las primeras experiencias formales de penetración directa de Inglaterra en el comercio hispanoamericano ${ }^{20}$. Acostumbraban escribir directamente, o confiaban a algún caballero ilustrado de la tripulación la relación y el testimonio escrito de cuanto veían y oían,

20 El ataque y pillaje, en su ruta a América, de las posesiones portuguesas en el mar y costa occidental de Africa eran para ellos legítimos objetivos, por haber sido desde 1580 hasta 1640 del Rey de España, enemigo natural de la orgullosa Albión, también Rey de Portugal. 
los cuales por estos diligentes esfuerzos se han conocido, conservado y han llegado hasta nosotros ${ }^{21}$.

En una escueta relación del segundo viaje negrero clandestino de John Hawkins realizado en 1564, John Sparke, miembro de la Compañia, describe a los apuestos y fornidos negros de Cabo Verde, considerándolos los "mejores de todos", al punto que intentó tomar algunos por la fuerza.

La narración del viaje de Andrew Barker, compilada por Richard Hakluyt, deja testimonio de su tránsito en 1576 por la isla del Sal, en cuya cercanía pescaron tortugas, y por la isla de Mayo, donde además de aprovisionarse de agua fresca incendiaron dos de sus pequeñas aldeas.

Francis Fletcher, capellán en un viaje a las costas de Brasil armado por Francis Drake hacia 1595, nos legó un pintoresco manuscrito en el cual describe la isla de Mayo como "verdeant", reforzando la descripción con un significativo bosquejo que enmarca la isla entre frondas.

La expedición organizada por Anthony Sherley en 1596 con el fin de atacar las posesiones portuguesas en el litoral africano, narrada por el maestre Thomas Masham, relata la dramática enfermedad del general en las cercanías de Cabo Verde, la cual atribuyen a las costas "contagiosas y sucias". Desembarcaron en Praia, "ciudad muy linda" de la Isla de Santiago donde el general se recuperó e intentaron adueñarse de los castillos, que reconocieron muy bien ubicados, guarnecidos y protegidos, lográndolo sólo parcialmente. Tomaron "la isla llamada Fuego, muy pequeña, con un monte muy alto en su centro que llamea constantemente... inaccesible por naturaleza, circundada por altísimos riscos". En el mes de setiembre presencian y describen, quizás sin percatarse de lo que en realidad ocurre, una erupción volcánica menor que los sorprende y maravilla:

...Sufrimos una noche una copiosa llovizna de cenizas, que se abatió tan densa sobre nuestra nave desde ese monticulo prendido en fuego, que podiamos' escribir nuestros nombres con el dedo sobre cubierta...

Durante el tercer viaje de Walter Raleigh en 1596, el caballero y tripulante Thomas Masham, señala la gran abundancia de sal que, junto con una gran cantidad de pescado fresco y de cabras "que es increible para quienes no las hayan visto y es maravilloso que puedan vivir juntas en una tierra estéril y pedregosa", se encuentra en las islas de Sal y de Mayo, motivo por el cual muchos veleros recalaban alli:

... Hay copiosidad de sal en esta isla forjada por la mano de Dios, sin intervención alguna del quehacer del hombre. Vimos fondeados seis veleros flamencos abasteciéndose de sal, que habian traido sus bestias, carretas, carretillas y rampas para que sobre éstas pudieran desplazarse aquéllas. Supimos que habia otros treinta veleros que se hallaban a sotavento de Fuego, los cuales también habian venido en pos de la sal.

21 La selección documental que presentamos a continuación sobre las islas de Cabo Verde y a la costa africana ha sido extraída de los volúmenes de Hakluyt, de los de Purchas y de la obra The World Encompassed (Ms. Sloane Ms 61), citados en la Bibliografia. 
Este tráfico puede ser muy ventajoso para Inglaterra considerando el elevado precio de este mineral...

También puso rumbo hacia el archipiélago, en 1601, William Parker, quien desembarcó en Saint Vincent con cien hombres y se apropió de la isla y su ciudad la cual hizo saquear y luego incendiar por sus soldados aunque reconociera que era "un hermoso lugar".

De otras voces, andanzas, incursiones y comentarios diversos, se nutre un singular compilador, un erudito cronista que logra reunir y reseñar diferentes visiones y memorias de $\tan$ controvertido territorio. No podemos soslayar su obra, que aunque no sea testimonio directo de un navegante, acoge y encierra la copiosa información de numerosos tratantes holandeses, viajeros, solicitantes, negociantes y armadores, en relacio a la ruta de las islas. Nos referimos a Joannes de Laet y a su extensisima obra Historie Ofte Laerlijk Verhael (Historia o Anales de los hechos de la Compañia Privilegiada de las Indias Occidentales), escrita en los albores del S. XVII, publicada en Leyden en $1644^{22}$, que constituye una fuente de gran importancia tanto para el esclarecimiento de la formación y actuación de la Compañía Holandesa de las Indias Occidentales, como para la Historia de la primera época del domino holandés en las Costas y Tierras de Brasil, que nos aporta múltiples e interesantes datos de otros viajeros, además de distintos testimonios en relación a los territorios de la costa africana y las islas de Cabo Verde.

En su calidad de Director de la Compañia en la Cámara de Amsterdam, Johannes de Laet, contemporáneo a los hechos que narra los cuales se extienden de principios de 1624 a finales de 1636, reúne y proporciona un extraordinario acopio de informaciones de primera mano, políticas, económicas, históricas, geográficas, analizadas en todos sus detalles, que abarcan la navegación de los navíos holandeses desde los puertos del norte a la costa oriental de Venezuela y Brasil, tocando islas y tierras africanas a la ida y a la vuelta.

Al igual que los ingleses, los navegantes holandeses evitan el paso por las Canarias o Madeira, posesiones españolas: prefieren bordear la costa africana y tocar las más confiables islas de Cabo Verde para abastecerse, en la larga ruta al promisorio Nuevo Mundo.

Las motivaciones que animaban a estos viajeros eran otras bien distintas de las simples ansias de exploración, reconocimiento o enriquecimiento fácil. Enfilan hacia América con el archipiélago en su ruta, con un objetivo bien definido: socavar las bases del poderoso imperio español, destruyendo los establecimientos y avances de España tanto en tierra firme como en territorio insular, saqueando y hundiendo los navios de aquella poderosa flota.

De nuestra propia traducción aún inédita vamos a transcribir algunos párrafos de los Libros I,VI y VII' ${ }^{23}$. El primero de ellos ofrece precisas informaciones sobre los derroteros y una prolija descripción de algunas de las islas:

22 La Hisforie Ofte Laerlijk Verhael se compone de 13 libros. La traducción al castellano que hemos llevado a cabo, aún inédita, arroja unas 1500 páginas mecanografiadas.

23 La primera descripción extraida del Libro I, corresponde al año de 1630. Las siguientes aportan consideraciones relativas a años anteriores. 
...La isla de $S$. Vicente es un tanto rocosa y montañosa, teniendo en la bahia oriental buen sitio donde anclar a 6 brazas de agua. Hay abundancia de pescado muy sabroso y buenos camarones, gran cantidad de tortugas, en la época apropiada, y pocos chivos, pues parece que los habitantes de la isla de Santo Antonio los habian cazado, asi como los que encontraron en Santa Luzia. Alli nuestra gente también estuvo, habiendo apenas cazado cinco chivos y en S.Vicente unos 300, pero con mucho trabajo. Hay grandes valles, pero ningún rio o riachuelo, y para obtener agua es necesario excavar pozos. Nuestra gente fue a Santo Antonio y tuvo buen acogimiento por parte de los habitantes. Ellos son en su mayor parte negros, habiendo algunos mulatos; se mantienen en el lado noroeste, donde tienen una aldea de cerca de 52 familias bajo el mando de un capitán, tienen un padre y todos hablan bien el portugués. Son una gente pobre $y$ con pocos recursos, - apenas un buen pomar de naranjas, limones e higos, situado a cerca de 400 a 500 pasos de la playa, junto a una punta baja y sobresaliente del mar. Se puede desembarcar del lado este, en chalupas, en vista de que alli es muy plano. El punto es fácil de reconocer: es un cabo bajo y plano y un poco a oeste, existiendo en el interior dos grandes colinas. El pomar está ubicado en un profundo valle y es rodeado de un lado por montes y del otro por muros. Los pilotos, habiendo tomado la latitud exacta de la isla, hallaron que está a 16 grados y 53 minutos al norte de la linea. Estas islas son un total de 11 y están situadas entre 14 y 18 grados al norte de Ecuador, siendo la isla de Santiago la principal, la más fértil y la más habitada. Algunas son desiertas y completamente estériles y en las que son más habitadas los pobladas son en su mayor parte malhechores desterrados de España y Portugal...

El trozo siguiente relata con gran detalle y vividas descripciones las particularidades del comercio entre las islas:

...Habiendo sido debidamente organizado el comercio de Guinea y otros lugares de Africa y América, los directores, que para ese entonces administraban la Compañia, comenzaron a deliberar a que proyecto echarian mano, para mejor debilitar los enemigos del Estado; puesto que sabian que no satisfacian los deseos de los leales habitantes de las Provincias Unidas, ni correspondia a la expectativa general de grandes cosas, con promover unicamente aquel tráfico, que ya era realizado por otros con anterioridad. Además, no se deberia esperar obtener pronto grandes ganancias y provechos del comercio con salvajes, aún no reducidos a la obediencia por el rey de España (con excepción del comercio de Guinea, cuyas ventajas eran por todos conocidas): esios pueblos bárbaros carecian de poco, tan sólo poseian hachas, cuchillos, corales y otras bagatelas semejantes. Y, debido a que no andaban vestidos, no se les podian llevar las mercancias fabricadas en el pais, o traidas para ellos; además, las mercancias que se obtenian de ellos a cambio, como maderas, tintas y cosas parecidas, más bien llenarian el mercado y no enriquecerian al pais...

En este último, continúa la acuciosa referencia con datos relativos al rumbo seguido por los navegantes holandeses y a los territorios explorados a su paso :

...Estos navios partieron de Texel a 22 de de Septiembre. A 12 de Octubre divisaron la isla Lanzarote, y entre 27 y 28 pasaron el trópico de Cáncer. El 30 estaban cerca 
de Cabo Blanco, y subieron pegados a él, arrimándose al viento que era de sureste. Se aproximaron del cabo hasta unas cinco brazas; con buen fondo. Al medio dia estaban a una altura de 20 $0^{\circ} 0^{\prime}$; después del medio día fueron entrando con viento del lado del mar, llegando, por la noche, a cuatro leguas hacia adentro del cabo. Este cabo es muy escarpado, como cortado a machete, saliendo de él una restinga de arena. Al dia siguiente lanzaron las chalupas y botes al mar: Esto no sólo para ir de pesca, sino también para investigar todas las ensenadas de la costa y ver si encontraban algún navio enemigo, pues muchos de ellos acostumbraban a pescar en estos lugares. En esta oportunidad no habia ninguno, por lo que los nuestios se fueron de alli. El 4 de Noviembre decayeron hacia adentro o norte de Cabo Verde. aproximándose en la noche de éste. Navegaron hasta la isla que queda en frente del mismo cabo y alli permanecieron. Al dia siguiente anclaron delante de "Refrisco" (¿Rufisco?), aldea de negros en la costa de Africa, donde hay libertad...

Por tratarse de una apasionante labor de rastreo histórico y rescate de enriquecedores testimonios sobre tan significativo territorio y trascendental momento, sería conveniente continuar indagando en crónicas, cartas, relaciones, portulanos, las descripciones de las islas de Cabo Verde vistas por los primeros navegantes que tocaron sus costas, rumbo a América, que aquí hemos abordado sin ánimo de agotarlas.

El archipiélago mostraba para cada viajero una faz diferente, un gesto distinto. Comparando estas tan diversas voces (de descubridores, navegantes, mercaderes, negreros, corsarios, buscadores de oro y riquezas, guerreros deseosos de cimentarse en batallas, aristócratas en pos de prestigio, almirantes ansiosos de lucirse en la confrontación con la armada española), podríamos quizás conformar una imagen que trascienda el tiempo y las circunstancias histórico-geográficas, una verdadera semblanza insular de Cabo Verde. Podriamos además seguir la evolución de las Hespérides a lo largo de los siglos, en una comprensión siempre más profunda, fiel, acertada del importante papel que jugó el archipiélago en la ruta de los descrubrimientos.

\section{BIBLIOGRAFÍA}

BENZONI, Girolamo. La Historia del Mundo Nuevo. Traducción Marisa Vannini de Gerulewicz. Caracas, Biblioteca de la Academia Nacional de la Historia. $1^{\mathbf{a}}$ ed. 1967, $2^{\mathrm{a}}$ ed. 1987.

BRUNI CELLI, Blas. Venezuela en 5 siglos de Imprenta. Caracas, Academia Nacional de la Historia. 1998.

CARLETTI, Francesco. Ragionamenti del mio Viaggio intorno al mondo 1594-1606. Torino. Ed. Einaudi, 1958.

CEI, Galeotto. Viaje y descripción de las Indias (1539-1553). Traducción Marisa Vannini de Gerulewicz. Caracas, Fund. Banco Venezolano de Crédito. Colección V Centenario del Encuentro entre Dos Mundos, 1995.

CHIAPPELLI, Fredi. First Images of America (2 vols). Berkeley, University of California Press, 1976. 
COLOMBO, Cristoforo. I viaggi dopo la scoperta. Verona, E. Cassa di Risparmio di Verona, Vicenza e Belluno, 1985

COLOMBO, Fernando. Le Historie della vita e dei fatti di Cristoforo Colombo. Milano, Istituto Editoriale Italiano, 1957.

DA MOSTO, Alvise. Le Navigazioni Atlantiche. Milano, Istituto Editoriale Italiano, 1956.

D'ANGHIERA, Pietro Martire. Mondo Nuovo. Milano Istituto Editoriale Italiano, 1958.

DUDLEY, Sir Robert. The voyage of Robert Dudley to the West Indies and Guiana (15941595). London, Hakluyt Society, 1899.

GERBI, Antonello. La Disputa del Nuevo Mundo. Milano - Napoli. Ed. Ricciardi, 1975

GABALDÓN MÁRQUEZ, Joaquín. Muestrario de Historiadores Coloniales de Venezuela. Caracas, Ed. Ministerio de Educación, 1948.

GOSLINGA, Cornelius. The Dutch in the Caribbean. Gainesville, University of Florida Press, 1971

HAKLUYT, Richard. The principal navigations, voyages, traffiques and discoveries of the English nation. Glasgow, James MacLehose and Sons, 1903-1905 (12 vols).

LAET, Joannes de. Histoire oft jaerlyck verhael van de verrichtinghen der geoctroyeerde WestIndische compagnie zedert hacr begin tot het eynde van t'jaer 1636, begrepen in derthien boecken ende met verscheyde koperen platen verciet, beschreven door Joannes De Laet, bewint-hebber der zelver compagnie. Tot Leyden, by Bonaventure ende Abraham Elzevier. Anno 1644. Met privilegie.

LAET, Joannes de. Novus Orbis o Descripción de las Indias Occidentales. Introducción, traducción, notas de Marisa Vannini de Gerulewicz. Caracas, Universidad Simón Bolívar, Instituto de Altos Estudios de América Lanita, 1988 (2 tomos).

OJER, Pablo. La formación del Oriente venezolano. Caracas. Ed. U.C.A.B., 1966.

PIGAFETTA, Antonio. Relazione del primo viaggio intorno al mondo. Verona, Ed. Cassa di Risparmio di Verona, Vicenza e Belluno, 1983.

PURCHAS, Samuel. Hakluytus Postumus or Purchas His Pilgrimes. Glasgow, James MacLehose and Sons, 1905, 1907 (20 vols).

SASSETTI, Filippo. Lettere da vari paesi (1570-1588). Milano, Ed. Longanesi, 1970.

VANNINI, Marisa. Italia y los Italianos en la Historia y en la cultura de Venezuela. Caracas. Ed. Universidad Central de Venezuela. 1998 (30 ed)

VANNINI, Marisa. El Mar de los Descubridores. Caracas, III Conf. Naciones Unidas sobre Derechos del Mar, 1974. Fund. Promoción Cultural de Venezuela, 1989.

VESPUCIO, Américo. El Nuevo Mundo. (Cartas relativas a sus viajes y descubrimientos. Textos en italiano, español e inglés). Buenos Aires, Editorial Nova, 1951.

The World Encompassed. London. Hakluyt Society, 1854. 